\title{
Multirange, Audiofrequency Thermocouple Instruments of High Accuracy
}

\author{
F. L. Hermach and E. S. Williams
}

\begin{abstract}
Two new types of thermocouple instruments developed at the National Bureau of Standards are described. The first, called a volt-ampere converter, is used with a directcurrent potentiometer to make measurements of alternating-current voltage and current over wide ranges with an accuracy of 0.05 percent at frequencies up to $20 \mathrm{kc} / \mathrm{s}$. The second is a 0.5 -percent multirange thermocouple volt-ammeter incorporating simple circuits so that the thermal converter may be checked with the indicating instrument normally connected to it.
\end{abstract}

\section{Introduction}

There have been increasing needs for convenient portable instruments for measuring voltage and current over wide ranges with high accuracy at audiofrequencies. Instruments of better than 0.1percent accuracy are needed for standardizing or testing other instruments for precise laboratory measurements, and instruments accurate to onefourth or one-half percent, and with low temperature coefficients, are needed for the more routine measurements. For the first type of instrument $(0.1 \%$ or better), accuracy and stability are important requirements. Such an instrument need not be directreading, but should be portable and reasonably convenient to use. The second type of instrument $(0.5 \%$ or better) must be direct-reading and should have many ranges.

For the applications mentioned above, thermocouple instruments are best suited because of their inherent wide frequency range and high sensitivity, and because multiple ranges are easily possible. The generally poor stability, large temperature influence (up to $0.3 \% / \mathrm{deg} \mathrm{C}$ ), and low overload factor have in the past severely limited the accuracy of conventional instruments of this type and have deterred their use. However, recent work at the National Bureau of Standards $[1]^{1}$ has shown that these disadvantages may be overcome by using selected thermal converters $^{2}$ (often called thermoelements or thermocouples) as a-c-d-c transfer standards. Methods and equipment have been devised at the National Bureau of Standards for standardizing instruments with an accuracy approaching 0.01 percent at audiofrequencies. The equipment was designed to make a-c-d-c difference tests of instruments quickly and easily, and with the highest accuracy. Unfortunately, the equipment is not portable, and the methods for making ordinary a-c measurements are neither rapid nor convenient. This paper describes two new types

1 Figure in brackets indicate literature references at the end of this paper.

2 Proposed AIEE definition 30.89.040: A thermal converter is a device that consists of one or more thermojunctions in thermal contact with an electric heater or integral therewith, so that the electromotive force developed at its output terminals by thermoelectric action gives a measure of the input current in its heater. of portable thermocouple instruments developed at the Bureau for a-c measurements where rapidity and convenience of operation are of greater importance than the high order of accuracy required in primary standardization work. The first is called a voltampere converter and the second a thermocouple volt-ammeter.

\section{Volt-Ampere Converter}

\subsection{Principle}

The first instrument is a multirange volt-ampere converter to be used with a d-c potentiometer for measurements with 0.05 -percent accuracy at frequencies from $20 \mathrm{c} / \mathrm{s}$ to $20 \mathrm{kc} / \mathrm{s}$. Its basic principle may be seen in the elementary diagram of figure $1 .^{3}$ In this instrument the heater of a single thermal converter is connected in series with appropriate resistors for voltage measurements and is connected in parallel with appropriate shunts for current measurements. The resulting output electromotive force of the thermocouple is balanced against the voltage from an internal d-c "bucking circuit", B. Balance is indicated by the null reading of a built-in galvanometer, G. The heater is then switched to an internal d-c circuit, which is adjusted to give the same output emf and therefore equivalent heater current and voltage drop. The voltage, $V_{p}$, across a portion of this circuit is then measured with an external potentiometer and is multiplied by a simple factor to obtain the unknown alternating voltage or current.

From figure 1, under ideal conditions of negligible ac-dc differences, we have, for voltage measurements, since $I_{a}=I_{d}, V_{a}=I_{a} R_{v}=I_{d} R_{v}=V_{p}\left(R_{v} / R_{p}\right)$, where $R_{v}=$ $R_{m}+R_{h}$. From figure $1, \mathrm{~b}$, we have, for current measurements, since $V_{a}=V_{p}, \quad I_{a}=V_{a} R_{s}^{\prime}=V_{p} / R^{\prime}{ }_{s}$ where $R_{s}^{\prime}=\left(R_{s} R_{h}\right) /\left(R_{s}+R_{h}\right)$.

A consideration of the circuits and these formulas shows that the measured alternating quantities are not dependent upon the conversion characteristics $E=f(I)$ of the thermal converter. They are dependent only on the potentiometer reading and the internal resistors, which can be made highly stable and whose values can be determined with great accuracy.

\footnotetext{
${ }_{3}$ The principle of this instrument is briefly described in section 9 of reference [1].
} 

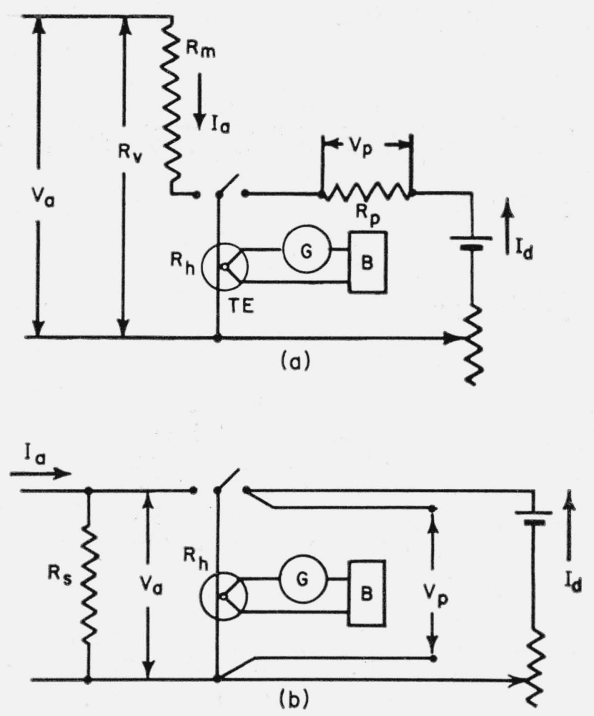

FIGURE 1. Elementary diagram of volt-ampere converter.

To realize this accuracy, however, the following requirements must be met:

1. The resistors must be properly adjusted and must be sufficiently stable.

2. The impedance of the a-c resistors, $R_{m}$ and $R_{s}$, must be equal to their d-c resistance to the desired accuracy.

3. The a-c-d-c difference of the thermal converter must be reasonably small over the desired frequency range.

4. The drift in the thermal converter and the internal d-c bucking circuit must be small enough that significant changes do not occur during a measurement.

5. The switches, wiring, and other components must be of the highest quality and with adequate insulation resistance. Switches and other contacting parts should show low and repeatable values of contact resistance and should not introduce objectionable thermal electromotive forces.

6. A null potentiometer of suitable range and accuracy must be used.

\subsection{Compensating Circuits}

The basic formulas show that the results are partially dependent on the heater resistance of the thermal converter, $R_{h}$. Because of its temperature coefficient, the value of the heater resistance is dependent upon the heater current. In addition, as explained later, the resistance may be permanently changed by moderate overloads, so that it cannot be relied upon with the same certainty as the other resistors in the circuit. Fortunately, for the usual current and voltage ranges, $R_{s} \ll R_{h} \ll R_{m}$, so that the heater resistance need not be highly stable and need not be known with great accuracy. However, it was found possible to modify the basic circuits so that this resistance need not enter into the formulas.
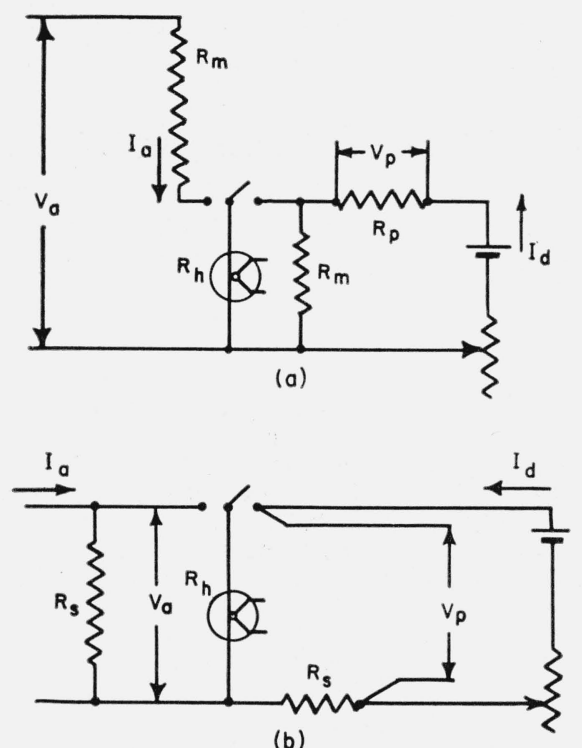

Figure 2. Compensating circuits for volt-ampere converter.

As shown in figure 2,a, the modification for voltage measurements consists in adding to the internal $\mathrm{d}-\mathrm{c}$ circuit a resistor, $R_{m}$, equal to the resistor (multiplier) connected in series with the thermal converter in the a-c position of the selector. For current measurements, as shown in figure $2, \mathrm{~b}$, a resistor, $R_{s}$, equal to the shunt resistance, is added to the d-c circuit.

From figure 2,a, we have, with the switch thrown to the left, $V_{a}=I_{a}\left(R_{m}+R_{h}\right)$. With the switch thrown to the right, we have $V_{p}=I_{d} R_{p}$ and $I_{h} R_{h}=\left(I_{d} R_{h} R_{m}\right)$ ! $\left(R_{h}+R_{m}\right)$, where $I_{h}$ is the current through the heater. Thus $V_{p}=\left(I_{h} R_{p}\right)\left(R_{m}+R_{h}\right) / R_{m}$ and, since $I_{h}=I_{a}$, we find that $V_{a}=\left(V_{p} R_{m}\right) / R_{p}$.

From figure $2, \mathrm{~b}$, we have, with the switch thrown to the left $\left(I_{a} R_{h} R_{s}\right) /\left(R_{h}+R_{s}\right)=\left(I_{h} R_{h}\right)$, where $I_{h}$ is the current through the heater. With the switch thrown to the right, we have $V_{p}=1_{d}\left(R_{h}+R_{s}\right)$. Thus, as $I_{h}=I_{d}$, we find that $I_{a}=V_{p} / R_{s}$.

Thus, rather remarkably, when these compensating circuits are used, the measured quantity is not dependent upon the heater resistance, $R_{h}$. The circuits are practical, and the added resistors (one for each voltage and current range) need be of only moderate accuracy.

\subsection{Description of Volt-Âmpere Converter}

A wiring diagram and a photograph of the instrument constructed in accordance with the principles and requirements just outlined are shown in figures 3 and 4 . The instrument combines both current- and voltage-measuring circuits, with switchselected ranges of $15,30,75,150$, and $300 \mathrm{v}$, and $0.1,0.25,0.5,1,2.5$, and 5 amp. It is completely self-contained and is intended for use with the usual general-purpose $1.5-\mathrm{v}$ null potentiometer of 0.01 - or 0.02 -percent accuracy. For these voltage ranges, the series resistances, $R_{m}$, are so high that there is 


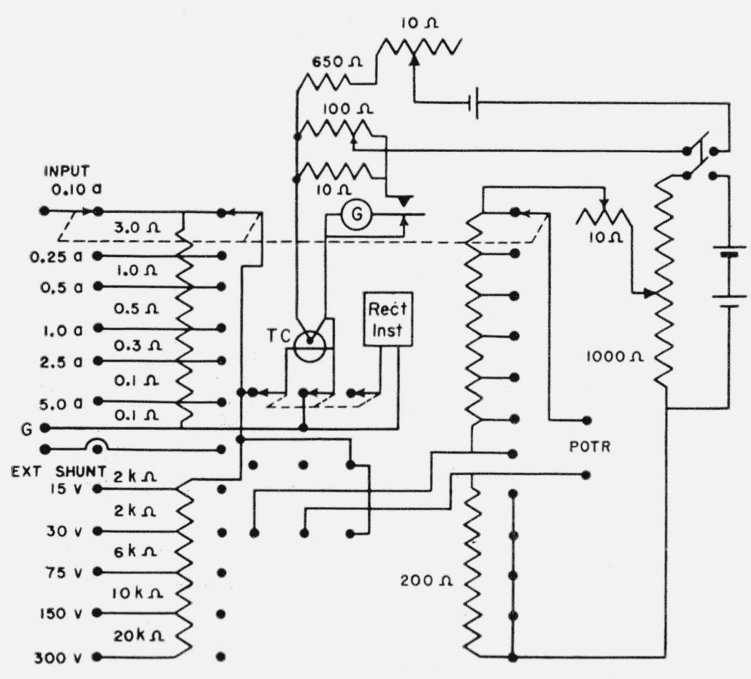

FiguRE 3. Wiring diagram of volt-ampere converter.

little need to compensate for heater resistance. The compensation for the current ranges was incorporated, however, and made it unnecessary to adjust each shunt to odd resistance values. The nominal output voltage, $V_{p}$, at rated input voltage is $1.5 \mathrm{v}$, and is $0.5 \mathrm{v}$ at rated input current. The latter value was chosen so that a series of $0.5-\mathrm{v}$ a-c shunts normally used at the Bureau for current-transformer testing could be connected to this instrument for measurements of currents above 5 amp [2].

A 7.5-ma, 10-mv thermal converter of the insulating-bead type (one thermocouple junction attached to the heater by an electrically insulating bead) is used in this instrument. Its a-c-d-c difference is not more than 0.01 percent at audiofrequencies. The a-c resistors for the voltage ranges and the two lowest current ranges are high-grade 0.05-percent audiofrequency resistance cards. The four-terminal bifilar (parallel-strip) a-c shunts for the 5- and 2.5amp ranges were constructed at NBS of 8-mil manganin strip $0.5 \mathrm{~cm}$ wide, with 4 -mil woven-glass tape as insulation. Bifilar shunts of No. 20 manganin wire were constructed for the 1 - and 0.5 -amp ranges. Considerable care was taken in connecting all of the a-c shunts to minimize inductive coupling between the current and potential circuits of the shunts. These arrangements were adequate to keep the a-c impedance within 0.05 percent of the $d-c$ resistance, even at $20 \mathrm{kc} / \mathrm{s}$. The wire and strip were initially annealed at $500^{\circ} \mathrm{C}$, and the completed shunts were aged at $150^{\circ} \mathrm{C}$ for $24 \mathrm{hr}$ before final adjustment.

The 200-ohm resistor, across which the d-c potentiometer is connected for voltage measurements, was made of manganin. The compensating resistors in the d-c circuit need not be carefully adjusted. Actually, 1-percent wire-wound resistors were used. The built-in light-beam galvanometer has a sensitivity of $0.3 \mu \mathrm{a} / \mathrm{mm}$, a resistance of $10 \mathrm{ohms}$, and an external critical-damping resistance of $30 \mathrm{ohms}$.

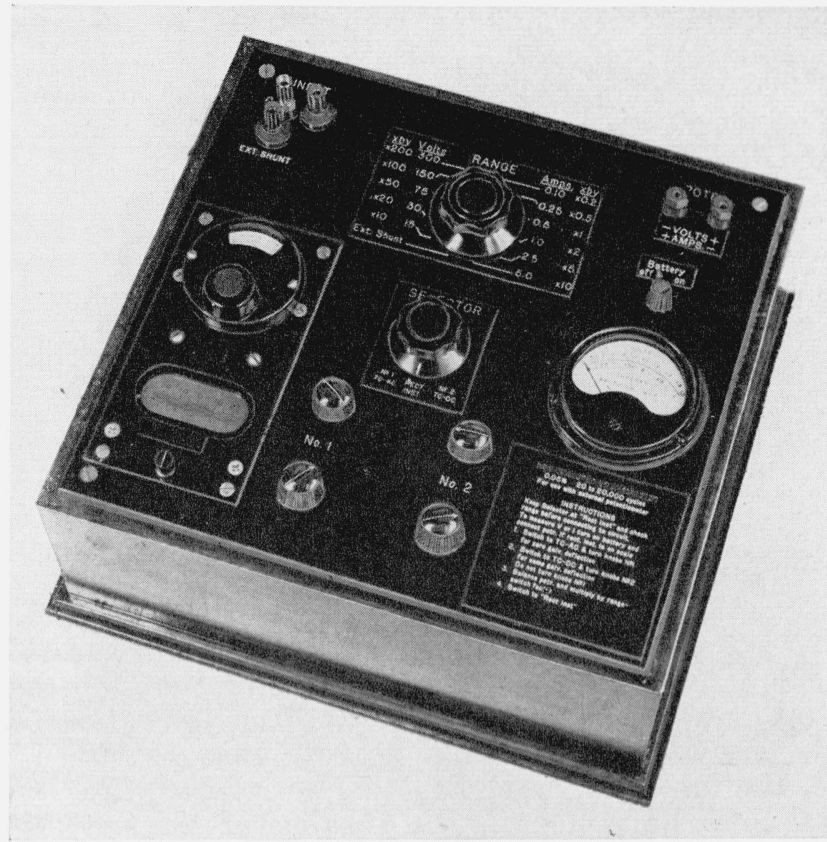

Figure 4. Volt-ampere converter.

Newly developed commercially available rotary switches with enclosed solid-silver contacts and a unique internal circuit are important components in the instrument. Mercury cells of 3-amp-hr capacity are used as the internal d-c sources because of their flat discharge-voltage characteristic and very long shelf life. The combined drifts in the balancing circuit and the thermal converter are less than $0.001 \% / \mathrm{min}$.

A useful feature of this volt-ampere converter is a 7.5-ma, 0.5- $\mathrm{v}$ rectifier instrument, which is switched in place of the heater when the thermal converter is connected to the internal d-c source. This instrument tells at a glance what effect circuit changes have on the measured current or voltage. It also indicates within 5 percent what voltage to set on the potentiometer. In addition, it can serve as a valuable overload protector, if the thermal converter is switched to the a-c circuit only when the rectifier instrument is on scale.

A spare 7.5-ma thermal converter having a bifilar manganin resistor in series with the heater, to adjust the total resistance to $66 \frac{2}{3}$ ohms \pm 0.6 percent, is mounted in the instrument. As the calibration of the instrument does not depend on the conversion characteristic of the thermal converter used, the converter, if burned out, may be replaced by this spare quickly and easily and without any effect on the accuracy of the instrument.

In use, the volt-ampere converter is switched to the desired range, and, with the selector on "Rect Inst," is connected to the circuit to be measured and to a suitable null potentiometer. If the rectifier instrument is on scale, the selector is switched to the No. 1 position to connect the thermal converter to 
the a-c circuit, and the controls of the bucking circuit (marked No. 1) are adjusted to bring the deflection of the built-in galvanometer to zero. ${ }^{4}$ The selector is then switched to the No. 2 position, and the controls of the internal d-c source (marked No. 2) are adjusted to give zero galvanometer deflection. The potentiometer is then balanced and read in the usual way, and the observed voltage is multiplied by the factor marked on the range switch of the volt-ampere converter to obtain the measured a-c voltage or current. Separate coarse and fine three-turn helically wound adjustable resistors permit both the No. 1 and No. 2 adjustments to be made reasonably quickly and easily and with the required precision.

\subsection{Tests of Converter}

Table 1 shows the results of a-c-d-c difference tests ${ }^{5}$ and of successive reversed d-c calibrations of the volt-ampere converter. They are an indication of the accuracy that is possible with this instrument. In the table the percentage d-c correction, $d$, is the value to be added to the reading of the potentiometer (connected to the "Potr" posts of the converter) to obtain the true direct voltage or current. The percentage a-c-d-c difference, $a$, is the percentage difference in voltage or current required for the same indication of the converter, a plus sign signifying that more alternating than direct voltage or current is required. For measurements that justify the application of these corrections, the alternating quantity, $Q$, being measured can be computed by the formula $Q=N V_{p}(1+a+d)$, where $N$ is the factor

\footnotetext{
${ }^{4}$ Actually, any deflection is permissible, provided that the same deflection is repeated with the selector in the No. 2 position.

5 These tests were made with the equipment described in reference [1]. The thermal converters and newly developed voltmeter elements have now been intercompared and tested at frequencies up to $1 \mathrm{Mc} / \mathrm{s}$.
}

marked on the range switch, and $V_{p}$ is the potentiometer voltage.

The d-c tests showed an early change in the 200ohm resistor across which the potentiometer is connector for voltage ranges but have not shown any other significant drifts. The heater of the thermal converter used in this instrument is of nickel-chromium alloy with a $+0.02 \% / \mathrm{deg} \mathrm{C}$ temperature coefficient. The resulting change in resistance with current (about $3 \%$ at rated current) causes the correction of the lowest voltage range to depend slightly upon applied voltage. Because of the compensation circuit, the change in heater resistance does not affect the accuracy of even the lowest current range.

The a-c-d-c tests show that the voltage ranges are useful to $200 \mathrm{kc} / \mathrm{s}$ and the current ranges to somewhat more than $20 \mathrm{kc} / \mathrm{s}$. It is believed that if thinner manganin strip and thinner insulation were used in place of the 4-mil strip and the No. 20 manganin wire for the shunts of the four higher current ranges, this frequency limit could be raised to $100 \mathrm{kc} / \mathrm{s}$.

\section{Thermocouple Volt-Ammeter}

\subsection{Principle}

The second instrument is a thermocouple voltammeter having a suitable millivoltmeter connected to the output of the thermal converter. The sustained accuracy in service of the usual instrument of this type is limited by the relatively high temperature coefficient of the combination $(0.1$ to $0.3 \% / \mathrm{deg} \mathrm{C})$, and by changes in the converter, probably due to stress relaxation of the heater, to moderate overloads, or to leakage of air into the evacuated bulb. It is often desirable, but seldom convenient, to test such

TABLE 1. Tests of NBS volt-ampere converter

\begin{tabular}{|c|c|c|c|c|c|c|c|c|c|c|c|}
\hline \multirow{3}{*}{ Range } & \multirow{3}{*}{$\begin{array}{c}\text { Applied } \\
\text { quantity }\end{array}$} & \multicolumn{4}{|c|}{ Reversed d-c corrections } & \multicolumn{6}{|c|}{ a-c-d-c differences } \\
\hline & & \multicolumn{2}{|c|}{1952} & \multicolumn{2}{|c|}{1953} & \multirow{2}{*}{$20 \mathrm{c} / \mathrm{s}$} & \multirow{2}{*}{$10 \mathrm{kc} / \mathrm{s}$} & \multirow{2}{*}{$20 \mathrm{kc} / \mathrm{s}$} & \multirow{2}{*}{$50 \mathrm{kc} / \mathrm{s}$} & \multirow{2}{*}{$100 \mathrm{kc} / \mathrm{s}$} & \multirow{2}{*}{$200 \mathrm{kc} / \mathrm{s}$} \\
\hline & & April & July & Jan. & July & & & & & & \\
\hline$v$ & $\begin{array}{r}v \\
300\end{array}$ & $\%$ & $\%$ & $\%$ & $\%$ & $\%$ & $\%$ & $\%$ & $\%$ & $\%$ & $\%$ \\
\hline 300 & $\begin{array}{l}300 \\
200\end{array}$ & $\begin{array}{r}+0.01 \\
+.01\end{array}$ & -0.04 & -0.04 & -0.04 & -0.01 & & -0.01 & - & & +0.08 \\
\hline 150 & $\begin{array}{r}150 \\
50\end{array}$ & $\begin{array}{r}+.01 \\
+.02\end{array}$ & -.03 & -.04 & -.06 & ...... & 0.00 & -.01 & . & -.02 & -.03 \\
\hline 75 & $\begin{array}{l}75 \\
50\end{array}$ & $\begin{array}{r}+.02 \\
+\quad 0\end{array}$ & -.02 & -.02 & -.04 & -..... & -.01 & -.01 & - & -.01 & -.02 \\
\hline 30 & $\begin{array}{l}30 \\
20\end{array}$ & $\begin{array}{r}+05 \\
+.02\end{array}$ & .00 & +.01 & -.02 & - & - & -.01 & , & .00 & .00 \\
\hline 15 & $\begin{array}{l}15 \\
10\end{array}$ & $\begin{array}{r}12 \\
+.06\end{array}$ & +.06 & +.08 & +.06 & -.01 & . & -.01 & ...... & .00 & -.02 \\
\hline$a m p$ & $a m p$ & & & & & & & & & & \\
\hline 5 & $\begin{array}{r}5 \\
3\end{array}$ & .00 & -.01 & .00 & -.01 & .00 & .00 & -.01 & -0.11 & -..... & -.....- \\
\hline 2.5 & ${ }_{2.5}^{3}$. & $\begin{array}{r}.00 \\
+.04\end{array}$ & +.02 & .00 & +.02 & 年 & .00 & $\begin{array}{r}.00 \\
-.03\end{array}$ & -18 & $\ldots$ & $\ldots$ \\
\hline 1 & 1 & +.01 & +.01 & .00 & .00 & -..... & -.01 & -.04 & -.27 & -...... & -....- \\
\hline 0.5 & 0.5 & +.01 & -.01 & -.03 & -.05 & $-\ldots$ & -.01 & -.05 & -.32 & -...... & ....... \\
\hline .25 & .25 & +.01 & -.04 & -.04 & -.04 & & -.01 & -.03 & & -.... & -..... \\
\hline .1 & $\begin{array}{l}.1 \\
.05\end{array}$ & $\begin{array}{l}+.05 \\
+.05\end{array}$ & $\begin{array}{l}+.04 \\
-\end{array}$ & $\begin{array}{l}+.04 \\
-\end{array}$ & $\begin{array}{r}+.05 \\
-\end{array}$ & $\begin{array}{l}-.01 \\
-\end{array}$ & -.02 & -.02 & $\begin{array}{r}-.08 \\
-\end{array}$ & ...... & - \\
\hline
\end{tabular}




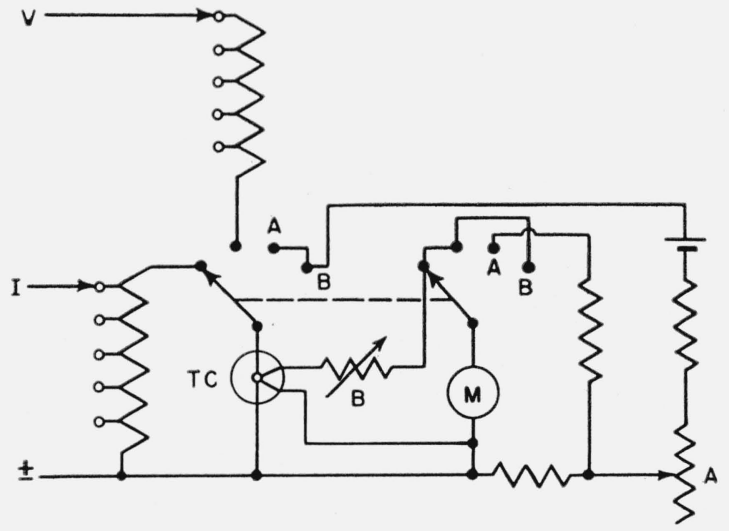

FIGURE 5. Elementary diagram of volt-ammeter.

an instrument by comparison with a d-c instrument at one scale point before important measurements are made with it. ${ }^{6}$ In this new instrument, the d-c millivoltmeter itself, together with appropriate resistors, is arranged as a milliammeter to provide for the important single-point check of the thermal converter, and adjustable resistors are incorporated to compensate for any changes.

Figure 5 is an elementary diagram of the circuit. With the selector switch in check position $A$, the heater of the 7.5-ma converter is connected to an internal $\mathrm{d}$-c circuit, and the millivoltmeter, $\mathrm{M}$, in series with a manganin resistor is connected across a 50-mv manganin shunt. The resulting milliammeter (7.5-ma full scale) has negligible temperature influence. Resistor $\mathrm{A}$ is then manually adjusted for full-scale deflection of the instrument, which corresponds to rated heater current. In check position B the millivoltmeter is connected to the thermocouple circuit, and resistor B is adjusted to give the same full-scale deflection, which is the correct deflection for this current. ${ }^{7}$ The checks can be made quickly and conveniently without disconnecting the leads from the terminals of the instrument.

\subsection{Changes in Heater Resistance}

Experience with thermal converters has shown, however, that additional precautions are necessary to insure complete accuracy in the measurement of current. The heater resistance of a converter may be permanently changed by as much as 0.5 to 1 percent by moderate overloads that do not burn out the converter. If the heater is shunted for current

\footnotetext{
${ }^{6}$ As an example, embarrassing errors were caused in a recent instance by a 10 -percent change in reading of a thermocouple voltmeter between regularly scheduled tests of the instrument, probably because of air leakage in to the glass bulb of the thermal converter.

7 An a-c "self-checking" instrument, which accomplishes the same end purpose as this instrument, but in a different way, has recently been developed commercially [3]. It uses a standard cell and galvanometer connected across a resistor as the direct-current standard.
}

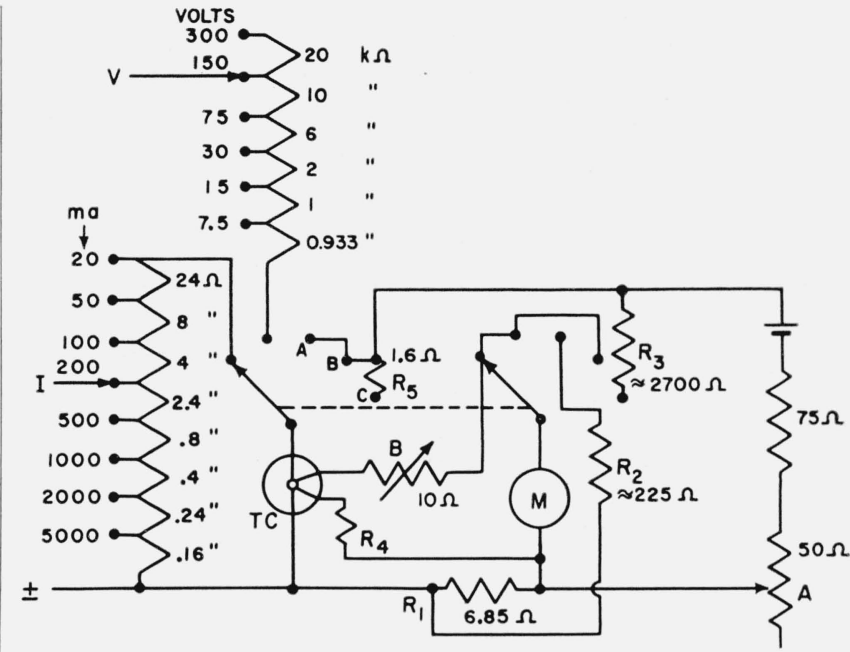

FiguRE 6. Wiring diagram of volt-ammeter.

measurements, such changes can cause an almost equal error. Furthermore, some alloys used for heaters have such a large temperature coefficient of resistance that the corresponding resistance change must be taken into account.

Table 2 shows the results of measurements of the permanent change in resistance caused by overloads of typical low-range thermal converters. In these tests the current was held for a few seconds at the overload indicated, and the change in resistance was then measured at normal current. The altered value of resistance was not affected by subsequent operation at rated current.

\section{TABLE 2. Effect of overloads on resistance of thermal converters}

\begin{tabular}{|c|c|c|}
\hline $\begin{array}{c}\text { Converter } \\
\text { range }\end{array}$ & $\begin{array}{c}\text { Rated } \\
\text { current }\end{array}$ & $\begin{array}{c}\text { Change in } \\
\text { resistance at } \\
\text { rated current }\end{array}$ \\
\hline$m a$ & $\%$ & $\%$ \\
5 & 200 & +0.5 \\
7.5 & $\left\{\begin{array}{l}200 \\
300\end{array}\right.$ \\
350 & +.9 \\
10 & $\left\{\begin{array}{c}200 \\
250\end{array}\right.$ & +.6 \\
\hline
\end{tabular}

To guard against errors due to changes in heater resistance, a circuit was provided in this instrument, as shown in figure 6 , for checking the heater resistance with the same millivoltmeter. In check position $\mathrm{C}$ the millivoltmeter, in series with manganin resistor $R_{3}$, is connected across the heater and shunt $R_{1}$. Resistor $R_{5}$ keeps the effective resistance of the battery circuit the same in this position as in check position $\mathrm{A}$, so that the battery current does not change. If the resistance of the heater of the converter has the proper value, the millivoltmeter will deflect to the full-scale mark. 


\subsection{Description of Volt-Ammeter}

The instrument (fig. 7) was constructed in accordance with the diagram in figure 6 . With this instrument, voltage and current can be measured successively in the same circuit without changing leads to the instrument. Ranges of $7.5,15,30,75,150$, and $300 \mathrm{v}$, and $20,50,100,200,500,1,000,2,000$, and $5,000 \mathrm{ma}$ are provided. The thermal converter is of the same type and range used in the first instrument, as are the a-c resistance cards for the voltage ranges. As in the other instrument, a bifilar manganin resistor is connected in series with the heater of the converter to adjust it to the proper value. An Ayrton-Mather ring shunt ${ }^{8}$ was constructed for the current ranges, with commercial a-c resistance cards for the four lower ranges and bifilar manganin. wire and strip for the higher ranges. Resistors $R_{1}$, $R_{2}$, and $R_{3}$ were wound of manganin, and after artificial aging, were adjusted to fit the $5-\mathrm{mv}, 25-\mathrm{ohm}$ millivoltmeter. $\quad R_{4}$ is in part a negative-temperature-coefficient resistor, which greatly reduces the temperature coefficient of the overall thermocouple instrument. The long-time stability of this resistor is not important because of the compensating circuit.

As shown in figure 7 , the range switches and input binding posts are on the left side of the millivoltmeter, and the selector switch and the helically wound adjusting resistors, $\mathrm{A}$ and $\mathrm{B}$, on the right. $\mathrm{A}$ submerged screwdriver-operated control prevents accidental rotation of resistor $B$. The temperaturesensitive resistor and the converter are mounted in the wooden box that houses the millivoltmeter.

As in the first instrument, the feasibility of these circuits depends upon the quality of the components. The leakage resistance, contact resistance, and thermal electromotive force introduced by the switches and adjustable resistors must not exceed certain easily computable limits. This is especially important in the low-voltage thermocouple circuit. Here, too, the enclosed silver-contact switches, originally

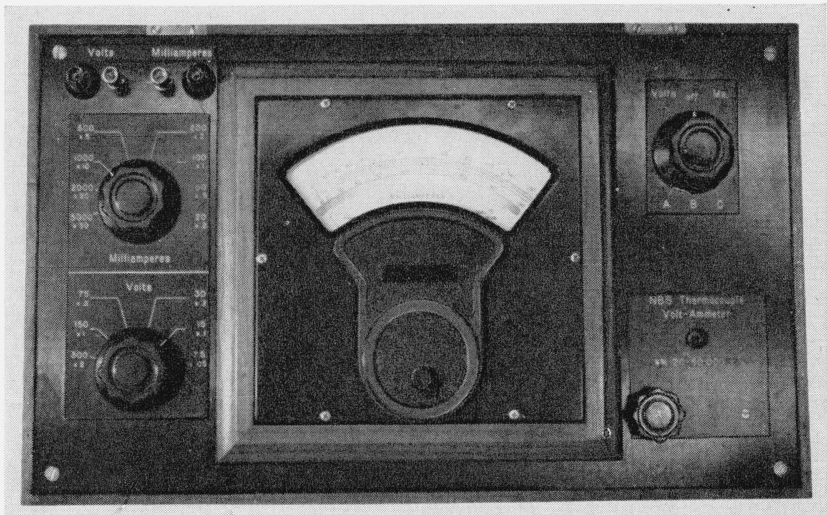

Figure 7. NBS volt-ammeter.

\footnotetext{
8 With a constant heater current, the ratio of the input currents on any two ranges for this type of shunt is independent of the heater resistance. Thus the same scale can be used for all current ranges in spite of the dependence of heater resistance upon temperature and therefore upon current.
}

developed for d-c potentiometers, are important components. Tests by the manufacturer indicate that in ordinary use the contact resistance of the switches are less than $0.001 \mathrm{ohm}$, the thermal electromotive forces generated are less than $1 \mu \mathrm{v}$, and the insulation resistance is greater than $10^{12} \mathrm{ohms}$.

No overload protection has been built into this instrument, but matched thermal converters have been selected for replacement. It has been found possible to select converters in this current range from larger lots, which match within 0.3 percent of full scale when adjusted for equality of millivoltmeter deflection at rated current, as in this instrument. Thus the expense of recalibration should not be necessary in case of burnout.

The instrument is used like any conventional thermocouple instrument. Readings are made directly in divisions and tenths of a division on a 100-division scale for the current ranges and a 150-division scale for the voltage ranges, and are multiplied by a simple factor given on the range switch to convert to volts or milliamperes. Besides simplifying the marking of the scale, this greatly reduces errors of estimating and reading. The checks can be made at any time, without disconnecting the leads from the circuit to the instrument, by simply rotating the selector switch to check positions $\mathrm{A}, \mathrm{B}$, and $\mathrm{C}$ in succession, and adjusting the A resistor for full-scale deflection of the millivoltmeter. Adjustment of the B resistor is rarely necessary, and only an overload or a very large temperature change could be expected to cause the reading in the $\mathrm{C}$ position to be in error. ${ }^{9}$

\subsection{Tests of Volt-Ammeter}

Table 3 shows the results of a-c-d-c difference tests and $\mathrm{d}-\mathrm{c}$ tests of the thermocouple instrument. In

TABLE 3. Tests at full scale of NBS 0.5-percent thermocouple volt-ammeter

\begin{tabular}{|c|c|c|c|c|c|c|c|c|c|}
\hline \multirow{2}{*}{ Range } & \multirow{2}{*}{$\begin{array}{l}\text { Applied } \\
\text { quan- } \\
\text { tity }\end{array}$} & \multicolumn{3}{|c|}{$\begin{array}{l}\text { Reversed d-c correc- } \\
\text { tions }\end{array}$} & \multicolumn{5}{|c|}{ a-c-d-c differences } \\
\hline & & $\begin{array}{l}\text { Oct. } \\
1952\end{array}$ & $\begin{array}{l}\text { Jan. } \\
1953\end{array}$ & $\begin{array}{l}\text { July } \\
1953\end{array}$ & $100 \mathrm{c} / \mathrm{s}$ & $20 \mathrm{kc} / \mathrm{s}$ & $50 \mathrm{kc} / \mathrm{s}$ & $100 \mathrm{kc} / \mathrm{s}$ & $200 \mathrm{kc} / \mathrm{s}$ \\
\hline$v$ & $v$ & $\%$ & $\%$ & $\%$ & $\%$ & $\%$ & $\%$ & $\%$ & $\%$ \\
\hline 300 & 300 & & & -0.1 & 0.0 & -0.1 & & -0.3 & \\
\hline 150 & 150 & 0.0 & 0.0 & -.1 & & -.1 & & -.1 & -0.3 \\
\hline 75 & 75 & .0 & +.1 & .0 & .0 & .0 & & .0 & -.1 \\
\hline 30 & 30 & -.1 & .0 & -.1 & & & & & -.1 \\
\hline 15 & 15 & -.1 & .0 & .0 & & & & & .0 \\
\hline 7.5 & 7.5 & -.1 & +.1 & .0 & .0 & .0 & & & .0 \\
\hline$a m p$ & $a m p$ & & & & & & & & \\
\hline 5 & 5 & -.1 & .0 & -.1 & & -.1 & -0.6 & & -..... \\
\hline 2 & 2 & -.1 & +.1 & .0 & .0 & .0 & -.3 & & - \\
\hline 1 & 1 & +.1 & +.2 & +.1 & .0 & -.1 & -.4 & & $-\ldots$ \\
\hline$m a$ & $m a$ & & & & & & & & \\
\hline 500 & 500 & .0 & +.2 & +.1 & .0 & .0 & -.2 & -.7 & - \\
\hline 200 & 200 & +.1 & +.2 & +.1 & .0 & .0 & -.1 & -.3 & \\
\hline 100 & 100 & .0 & +.2 & +.1 & 0 & .0 & & -.2 & - \\
\hline 50 & 50 & 0 & +.2 & +.1 & 0 & .0 & & -.1 & - \\
\hline 20 & 20 & -.1 & +.2 & .0 & .0 & .0 & & .0 & $\ldots$ \\
\hline
\end{tabular}

${ }^{\theta}$ If the heater resistance has changed, a correction to be applied to each current range can readily be determined from the resulting change in deflection of the instrument in check position C. Because an Ayrton-Mather shunt is used, the correction is the same on each current range. Calculations and tests show that the percentage of the indication to be added to the reading on any current range due to a change in heater resistance is approximately equal to the percentage increase in deflection in check position $\mathrm{C}$. 
this table the percentage correction is the value to be added to the indication of the instrument to obtain the true direct current or voltage, and the a-c-d-c difference is the percentage difference in alternating and direct current or voltage to produce the same indication. Only the tests at full scale are included in the table. Reversed d-c measurements were made at the time of the first test at every cardinal scale point on the $150-v$ and 2 -amp ranges. The observed correction in divisions at each of these cardinal points was adjusted by subtracting a proportional part of the observed full-scale correction that is, by subtracting $C_{f} D / D_{f}$, where $C_{f}$ is the full-scale correction, and $D_{f}$ and $D$ are the number of full-scale divisions and the number of divisions at that cardinal point, respectively). The plotted results, figure 8 , show the scale corrections for both scales and were verified by tests at two cardinal points on other ranges. Such a plot and a table of full-scale corrections for each range greatly simplify the application of corrections to the reading of a multirange instrument such as this. The d-c correction at any point is simply the scale correction plus a proportional part of the full-scale correction for that range, and is easily calculated mentally. The a-c value is simply the corrected $d-c$ value plus the a-c-d-c difference of the instrument (which is usually negligible). The $a-c-d-c$ difference and the scale corrections need be determined only once, and subsequent tests need be made only at full scale on each range with reversed direct current.

The results of the a-c-d-c tests of this instrument show negligibly small frequency influence on all ranges even at $20 \mathrm{kc} / \mathrm{s}$. Measurements at two cardinal points on several ranges showed no significant dependence of a-c-d-c difference upon scale position. The voltage ranges are actually useful to $200 \mathrm{kc} / \mathrm{s}$ or more, and the current ranges to $50 \mathrm{kc} / \mathrm{s}^{10}$

Tests of the temperature influence of the instrument were made on the $150-\mathrm{v}$ and 1 -amp ranges at temperatures between $25^{\circ}$ and $40^{\circ} \mathrm{C}$. The tempera-

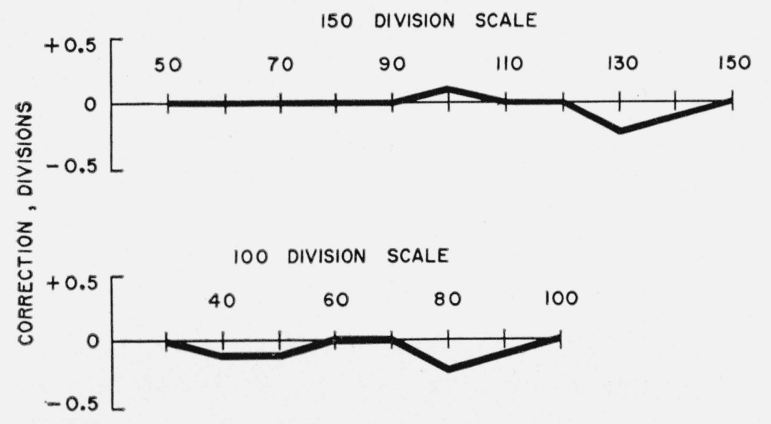

Figure 8. Scale corrections for volt-ammeter.

10 The instrument was originally constructed with a helically wound adjustable resistor in series with the heater of the thermal converter to compensate in check position $\mathrm{C}$ for any change in heater resistance. However, its inductance limited the frequency range of the instrument to $20 \mathrm{kc} / \mathrm{s}$, so that it was later removed, and the checking circuits were rewired in their present form. ture coefficients calculated from these results were less than $+0.02 \% /$ deg $\mathrm{C}$ before the checking procedure was carried out and were less than $+0.01 \% / \mathrm{deg} \mathrm{C}$ afterward. Preliminary tests had shown that the temperature coefficient of the instrument before the temperature-sensitive resistor and checking circuits were connected was about $+0.12 \% / \mathrm{deg} \mathrm{C}$, and that a large part of this arose in the thermal converter itself. It does not appear to be generally realized that thermal converters may have temperature coefficients ranging up to $+0.3 \% / \mathrm{deg} \mathrm{C}$.

These tests indicate that this instrument may properly be considered to be in the 1/2-percent-accuracy class and will remain within this accuracy over an extended range of temperatures. The construction of a $1 / 4$-percent instrument of this type might prove feasible, but would depend largely on the inherent stability and readability of the millivoltmeter. ${ }^{11}$

\section{Summary}

\subsection{Volt-Ampere Converter}

The volt-ampere converter can serve as an accessory to the d-c potentiometer to make possible the measurement of alternating current and voltage over a wide range of frequencies, just as a volt box or shunt box is used to extend the range of the potentiometer for d-c measurements. The formulas are the same in appearance as those used with a volt box or shunt box, and, indeed, the multiplying factor to convert the potentiometer readings to a-c volts or amperes are exactly the same as those that would appear on the d-c range-extending devices. Thus the volt-ampere converter, by an adaptation of the transfer principle, may be considered to extend potentiometric techniques to a-c volt-ampere measurements, with the following advantages:

1. High accuracy is possible - better than that obtainable with any portable deflecting instrument.

2 . This accuracy is realized over a greatly extended frequency range; 20 to $20,000 \mathrm{c} / \mathrm{s}$.

3. Without any attendant loss in accuracy, it is entirely feasible to construct a multirange instrument - one instrument can be designed to cover a wide range of measurement of both voltage and current.

4. The volt-ampere converter is portable, selfcontained, requires no external d-c source or controls, and is reasonably convenient and easy to use.

5. The accuracy of the volt-ampere converter is not dependent, as are other thermocouple instruments, on the long-time stability of the thermal converter used. As a consequence, a thermal converter can easily be replaced by another of the same range and heater resistance without affecting the accuracy of the volt-ampere converter and without requiring its recalibration.

${ }^{11} \mathrm{It}$ is recognized that a sensitive millivoltmeter suitable for indicating thermocouple electromotive forces is not as rugged, and therefore may not be as stable as the more usual d-c milliammeters, of ranges greater than about 2 ma, that utilize higher operating torques. 
6. To insure continued high accuracy, the instrument can easily be periodically tested on direct current by means of the potentiometer and its d-c accessories. The a-c-d-c differences are permanent and need ordinarily be determined only once.

7. The small rectifier instrument insures some of the advantages provided by a deflecting instrument, and, in the normal sequence of operations, can serve to prevent converter burnout.

The volt-ampere converter has the disadvantage of requiring two extra balancing operations for each measurement, but experience shows that these can be made quickly and easily. It has the weakness that inadvertent adjustment of the thermocouple balancing voltage instead of the heater current when the converter is on direct current can give erroneous results. This could be prevented, however, in a number of ways, such as by incorporating a mechanical device to disconnect the adjusting resistors of the bucking circuit when the converter is switched to the internal battery, or by providing a sliding cover plate, rotated by the selector switch so as to cover up the controls that should not be used.

\subsection{Thermocouple Volt-Âmmeter}

The 1/2-percent thermocouple volt-ammeter is a conventional multirange instrument, except that it is provided with additional circuits and components to permit using its indicating instrument to check the thermal converter, and with manual adjustments in the thermocouple circuit for compensating for converter changes. In addition to detecting and compensating for changes in the thermal converter, this makes possible a thermocouple instrument of very small temperature coefficient. The added circuits are simple, the components are inexpensive, and the instrument is easy to use. Although more limited in accuracy, this instrument retains many of the advantages of the volt-ampere converter, and is, in addition, direct-reading.

\section{Conclusions}

Two electrothermic instruments have been developed to meet specific needs at the National Bureau of Standards. The first serves as a standard for the a-c testing of ammeters and voltmeters in the $3 / 4$ percent-accuracy class or better that are sent in to NBS for certification. The second is used for general measurements at audiofrequencies and for tests of electronic and panel instruments, and, in conjunction with a suitable attenuator, has proved very convenient for the testing of electronic voltmeters. These instruments have been described because of their novelty and usefulness, and because it is believed that similar instruments may well meet like needs in other laboratories.

The development of these instruments, based on the transfer principle, has served to demonstrate the high order of accuracy attainable by this method for the measurement of both current and voltage over wide frequency ranges. The demonstrated gains overcome the limitations of conventional thermocouple instruments arising from temperature influence or the likelihood of changes in the thermal converter, and, it is hoped, will lead to wider laboratory use of electrothermic instruments.

\section{References}

[1] F. L. Hermach, Thermal converters as a-c-d-c transfer standards for current and voltage measurements at audio frequencies, J. Research 48, 121 (1952) RP2296.

[2] F. B. Silsbee, Notes on the design of four terminal resistance standards for alternating current, BS J. Research 4, 73 (1930) RP133.

[3] Electrical Measurements 19, No. 4 (Sensitive Research Instrument Co., Mt. Vernon, N. Y., 1952).

Washington, December 3, 1953. 